\title{
Status and Optimization Strategies Based Supermarket Chain of the Supply Chain and Distribution Mode
}

\author{
-Distribution Center Suguo Maqun as an Example
}

\section{Fangtao Jiang, Yiting Gao}

Jinling Institute of Technology, Nanjing, China.

Email: jft440835@126.com

Received October $21^{\text {st }}, 2012$; revised November $14^{\text {th }}, 2012$; accepted November $22^{\text {nd }}, 2012$

\begin{abstract}
With the development of supermarket chains in China, the competition intensified, logistics and distribution is gradually becoming a key factor of the competitive strength of the supermarket chains. The supermarket chain logistics development to some extent affects affected the development of supermarket chains. This paper analyzes the present situation of the distribution pattern of the supermarket chains, and target optimization strategies, trying to figure out Suguo supermarket, for example.
\end{abstract}

Keywords: Distribution Mode; Supermarket Chains; Strategy

\section{Introduction}

With the continuous development of China's economy in recent years, a lot of supermarket chains spread all over our country city and countryside, the competition of supermarket chains becomes more and more fierce. Supermarket chains that are to achieve long-term advantage in the fierce competition in the development, must optimize the logistics present situation to improve the emphasis on the role of the distribution center, to improve logistics efficiency, in order to achieve the purpose of reducing logistics costs and enhancing the competitiveness of enterprises. At the same time, supermarket chains should strive to provide high variety, low prices, reliable quality and timely delivery of goods and provision of quality services to meet consumer demand.

\section{Introduction of Several Related Concepts of Supermarket Chain Distribution Mode}

\subsection{Supermarket Chains}

Supermarket chains that operate the same category of goods and after-sales service supermarket certain merged into a unified whole, the standardization of the appearance of the image by the enterprise, the specialization of the operation and management activities, organization and personnel standardization and modernization of internal management tools do achieve relatively simplistic, so as to achieve the economies of scale to make complex business activities. Supermarket chains carry out a low- price, low-margin, high-turnover business in the price system; take open-shelf sales in the way of sales, customer choice, and adapt to mass consumption, mass marketing, mass flow of new retail distribution means [1].

\subsection{Distribution Mode}

Distribution refers to choosing, processing, packing, segmenting, matching, assigning, delivering the goods on time to a designated location according to the customer requirements in the economic and reasonable area range [2].

The distribution mode is divided into self-distribution, joint distribution and the third-party distribution. Selfsupporting distribution refers to the enterprise distribution in various links by the enterprise itself, then set up the planning and organization management to realize the enterprise internal and external shipping mode. The joint distribution is complementary distribution pattern of cooperation between enterprises, created a function to improve efficiency and achieve the rationalization of distribution. The third-party distribution with certain scale and specialized in the distribution of third-party distribution enterprise, using its own assets and business forms, and the mode of delivery services to the users in a defined area [2].

\subsection{Supply Chain}

Supply chain refers to surround the core enterprise, through the control of information flow, logistics, capital 
flow, starting from the procurement of raw materials, made of intermediate products and final products and sales network will deliver products to consumers in the hands of suppliers, manufacturing suppliers, distributors, retailers, and until the end-users together into a whole network structure.

\section{Present Situation and Optimization of Supermarket Chains Distribution Mode}

\subsection{Present Situation of Supermarket Chain Distribution Mode}

1) Managers misunderstand the distribution center.

Logistics research in China starts late and does not have a deep understanding of the distribution center and practice is insufficient, many supermarkets have seen the distribution center as a simple storage and transport of goods organization instead of a customer-centric service philosophy. The managers did not realize that the services provided by the distribution center are a valueadded service. Even some enterprises renamed the original warehouse distribution centers, this just increases the number of transport equipment, from ostensibly distribution center as a temporary storage location of a commodity turnover, which makes the level of logistics distribution center not apply to the operation and management of the modern supermarket chains demand, not maximize the role of the distribution center.

2) Outdated concept of supermarket chain logistics management.

Many supermarket chains lack the operational capacity of the logistics operations at the strategic level and the tactical level. There are two different tendencies. First, many chain retail enterprises in expanding the scale only concerned about the expansion of the store and neglected the construction of logistics and distribution system. As a result, many problems come out in the background logistics system architecture and management; there the foreground growing number of shops at the same time, but the total profits of the enterprise are declining. There is also a tendency for some large retail chains to establish their own logistics and distribution system. It has not led to the formation of scale, self-management logistics huge direct investment in warehousing, transportation, labor, equipment, space, equipment operations, maintenance fees and merchandise turnover occupied capital directly increases the operating costs of enterprises [3].

3) The distribution is not the formation of scale and operating costs are high.

Distribution is not the formation of scale, distribution intensification of low, mainly manifests in two aspects: First, the supplier direct distribution mode, suppliers rush to the supermarket chain stores of goods, can not make full use of social resources, leading suppliers high oper- ating costs, the number of suppliers of vehicle simultaneous delivery may also cause traffic congestion to accept the goods, and also make it complicated and difficult to coordinate the organization, and thus to increase the delivery time and improve the transportation costs, which is passed on to the supermarket chains [4]. Day-today operating performance, chain stores, distribution centers operating efficiency will affect supermarket chains and lead to the formation of the invisible cost, at the same time the level of efficiency of information exchange in shops and suppliers will have a certain impact on the operation of the supermarket.

4) The scale of self-distribution is small, distribution operating system is imperfect and efficiency of distribution is low.

In recent years, a number of supermarket chains establish their own distribution centers based on their own circumstances, but mostly the transformation was completed on the basis of the original warehouse, the scale of self-distribution is small and not complete, so the uniform distribution is low only about $50 \%$, most enterprise unified distribution rate, resulting in idle, transport equipment can not be taken full advantage of, thus cause the high cost of logistics. And a relatively low level of computer applications in distribution centers, mostly done manually. Logistics outdated technology and equipment, and information processing technology are so backward. Self logistics are many varieties of goods less bulk distribution. It has not formed a perfect distribution operating system yet.

5) Low degree of modernization of the distribution center.

Since the logistics develop in our country, China's logistics and distribution of the infrastructure investment is less, the development is slow investment. Although in recent years, some state-of-the-art warehousing and logistics facilities are upgraded, but from an overall point of view, China's logistics and warehousing facilities are still obsolete, function is far from complete, warehousing and logistics facility structure is irrational. Little mechanization and automation of operations, loading and unloading of cargo by artificial completed, all of this have led to the phenomenon of low operating efficiency, high breakage rate and high error rate. It can not meet the requirements of modern chain of logistics distribution. Converge on the various links in the logistics supporting service function is imperfect, can do "one-stop" service. Although part of the chain of distribution centers has achieved the standardization of operating procedures, but only stay in the simple handling of goods, because of the lack of information processing, computer applications only in its infancy and the low degree of modernization of the distribution center. 


\subsection{Optimization Strategy of Supermarket Chain Distribution Mode}

1) To deepen the understanding of the distribution center and improve the management level.

Understand the important role of the distribution center for supermarket chain correctly, rather than previously as an ordinary warehouse, it is a link between the production and retail, it combines business flow, logistics, and information flow together. The business philosophy of the modern supermarket chains and distribution center should rely on the quality of service capture the market, rely on advanced management, technology reap the benefits. Distribution center sales agents have the basic functions of the distribution transshipment, order processing [5], delivery of goods, information transfer, high quality and quick completion of the above work, in order to avoid the cost and time losses in the distribution process of goods produced by the supermarket chains in the past. The decision makers of the company should change the traditional business concept, enterprises by the central role of the distribution center, the circulation scale enlargement, to achieve the desired economic benefits. Through a highly centralized procurement and distribution behavior, make each shop in the organization of the purchasing behavior to achieve scale enlargement. Or combine scattered, sporadic store merchandise and distribution together, and make it unified by a professional wholesale company or distribution center, the formation of certain economies of scale, the various shops benefitsharing, thereby expanding the distribution scale, forming a virtuous circle.

2) Update the concept of traditional logistics, absorb logistics personnel.

The regional government departments should put in a certain amount of human, material and financial resources, and constantly enhance the awareness of the universal logistics distribution center to improve the quality of logistics practitioners. Accelerate the cultivation of human resources development of modern logistics, support and encourage the training and the introduction of various forms of multi-level logistics professionals. Update the traditional concept of the development of China's logistics center to provide personnel protection. Through the cultivation of high-quality logistics personnel to speed up the exploration of China's logistics center in-depth study and practice test, and thus lay the foundation for the development of China's logistics distribution center.

3) Commodity distribution scale, arise the efficiency of delivering goods, reduce costs.

According to the enterprise branch location and distribution of the different requirements to arrange delivery frequency, delivery quantity and delivery routes, com- modity distribution scale, give full play to the existing distribution tools and should also take into account of the role of personnel and logistics costs, in order to improve the efficiency of product distribution, and reduce costs. Supermarket chains reduce costs in order to ensure the goods inexpensive, to make them in favor of consumers and make supermarket chains become bigger and stronger.

4) Establish a distribution center for supermarket chains.

Distribution center is important for the development of supermarket chains, but enterprise must select the appropriate form of the establishment of the supermarket chain distribution center, otherwise it will not be able to play the dominant role of the distribution center. Supermarket chains should choose the development rationally by own size, capital position and prospects. Supermarket chains should adopt a unified planning, centralized deployment, distribution, implementation, and step-by-step strategy in place. Scale of self-logistics is small, we want to improve the system of distribution operations, raise distribution efficiency. In fact, for the supermarket chain, the development of a wide range of distribution form, it is worth the attention of small, medium and large supermarket chains.

5) To improve the degree of modernization of the distribution center.

First, the area of modern distribution center operations is very large, and it should be with automatic sorting machine, electric lifts, automatic conveyor, vacuum packaging machines and other machinery and equipment, and the use of automation management, it can provide fast and accurate delivery service. In order to achieve economies of scale, distribution centers must pass a logistics role, computerization and management of the delivery of goods, the use of specialized storage and transportation equipment and modern information systems, logistics operations to achieve automation and efficiency; Secondly, the distribution center is specialized in cargo distribution logistics spaces or economic organizations, and it is processing, cargo handling, delivery and other functions into one logistics node. We should continue to develop distribution centers into purchase functions, sorting functions, processing functions, storage functions, distribution functions, information processing functions and then into one node.

\section{Take the Suguo Maqun Logistics Distribution Center as an Example to Analyze the Status of the Delivery Mode and Optimization Strategy}

\subsection{Suguo Maqun Distribution Center Introduction}

The Suguo Maqun distribution center is located in Qixia District, Nanjing Maqun Information Science and Tech- 
nology Park, the traffic is very convenient. The park covers an area of about $180,000 \mathrm{~m}^{2}$ distribution center and has currently the largest single high-bay warehouse. Main warehouses use the internationally accepted form of steel building, warehouse also supporting the electric sliding doors, lift tone platform, in order to reduce the day-to-day operating costs. In addition to the three-dimensional warehouse project, Suguo is planning agricultural products and fresh processing, distribution and processing of two, three engineering.

Adhering to the concept of modern logistics distribution center planning and design, and the mode of operation of the process efficiency and cost advantages, and the extensive use of advanced, mature technology and equipment: 1) logistics information system with the international advanced level professional warehouse management software (SSA Exceed 4000), has oriented task management, real-time inventory status management, support multiple distribution centers, multi-shippers management, open extensions and many other advanced features; 2) the use of wireless network technology and the handheld RF radio frequency terminals and other technical equipment, support logistics paperless; 3 ) the use of a leading modular shelving systems, over 10 meters in height and in accordance with the three-dimensional warehouse multilayer cargo space, database handling the actual needs of the long distance, the use of the 72 sets imported from Germany, Sweden, excellent performance electric vertical horizontal handling equipment and a series of state-of-the-art logistics technology equipment, improve space utilization and efficiency of logistics operations; 4) to adapt to the development needs of the three-dimensional warehouse planning and reservation automatic sorting machine, electronic tag system device interface, the time is ripe that available on-line operations, and enhanced logistics and distribution capabilities; 5) has a variety of room temperature, insulation van owned trucks of more than 60 units, the introduction of a geographic information system (GIS) and vehicle management system, the use of a car GPS technology not only greatly broaden the range of effective space transportation management, but also for further deepening of the logistics management, to enhance logistics service level to create a good technical condition.

Currently, Maqun distribution centers for more than 1000 Suguo stores at room temperature commodity distribution services, stores Suguo LAN receives daily orders, according to the store needs to implement a daily distribution, fulfill general orders within 24 hours, the radius of logistics services more than $250 \mathrm{~km}$. In addition, Maqun distribution socially oriented customers to provide wholesale, third-party logistics services. In 2005, the peak day throughput distribution center has exceeded 30 million cases of more than 7 billion Yuan, total annual commodity throughput.

\subsection{Present Situation of Suguo Maqun Distribution Center}

1) Construction cost and investment risk. Maqun logistics distribution center is a total investment of about 200 million Yuan, larger investment brings greater risk. Once a problem affects the operation of the logistics center, it even affects the supply and sales of Nanjing Suguo.

2) Distribution scale lack of flexibility while distribution area of single customer structure. Logistics and distribution center in Maqun targets only major Nanjing Suguo supermarket distribution center logistics services over a radius of 250 kilometers, but still of weak distribution of scale and high cost of logistics situation.

3) Lack professional staff. Due to slow start of logistics in China, lack logistics personnel, leading to poor management and logistics resources are not maximized application. Companies recruit a large number of students every year, but because of the long study period, they eventually keep very few.

4) The lack of a complete supply chain support, supply risks remain. An ideal logistics and distribution center operations management system should be established in the supply chain management model to achieve the mutual benefit of the members of the supply chain. The information flow of the Suguo supermarket supply chain system is instable, logistics support is not solid and inter-organizational trust is temporary.

5) The lack of a comprehensive information platform support, lower operating efficiency. Imperfect information platform, not timely understanding of customer needs and unresponsive to make sensitive reaction to the market, will eventually lead to the low efficiency of the entire distribution system and distribution process.

\subsection{Optimization of Suguo Maqun Distribution Center}

1) To enhance the social distribution service capabilities, enhance the delivery of flexible, mining profit growth, diluted logistics center operating costs. Currently, East China and even China has not a society of supermarket logistics and distribution enterprises, therefore there is the phenomenon of low resource utilization in terms of equipment resources, management resources, to improve the utilization of these resources, socialization is an important way.

2) Improve direct flow gravity, reduce distribution costs. Direct flow delivery mode is characteristic of the goods to the warehouse cargo distribution center without after storage shelves, but direct transfer to the stores can greatly reduce distribution costs.

3) Establish a scientific accounting system, and accel- 
erate the transition to the profit center. To become a profit center, enterprise is necessary to do the social transformation of market-oriented operation. But this will take some time, as well as step-by-step implementation stage.

4) Accelerate the improvement of the supply chain system. Current supply chain procurement staff formed, the supermarket demand for commodities has instability such supply chain structure is usually shown as in Figure 1.

From a time point of view, the lack of long-term stable supplier of Maqun logistics distribution center can not support this as a supply chain system. To do this, how to focus on the logistics and distribution center, establish and improve the system as the core of supply chain Suguo becomes a focal point of thinking problems of Suguo supermarket. Logistics support and logistics services all gathered to logistics and distribution center, then the Suguo ideal supply chain structure model formed, as shown in Figure 2.

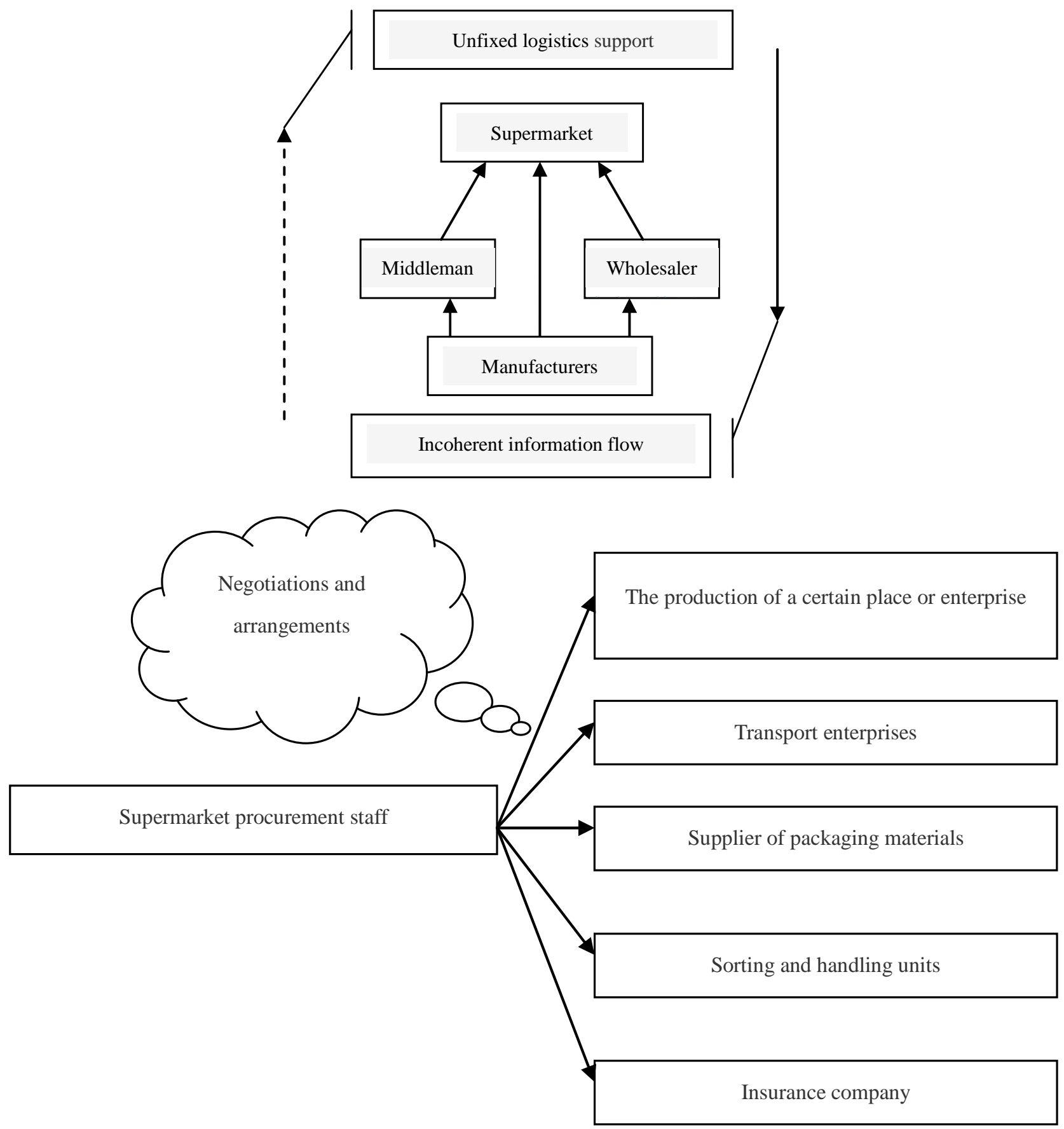

Figure 1. The inperctions supply. Temporary formation on of the supply chain procurement staff negotiations. 


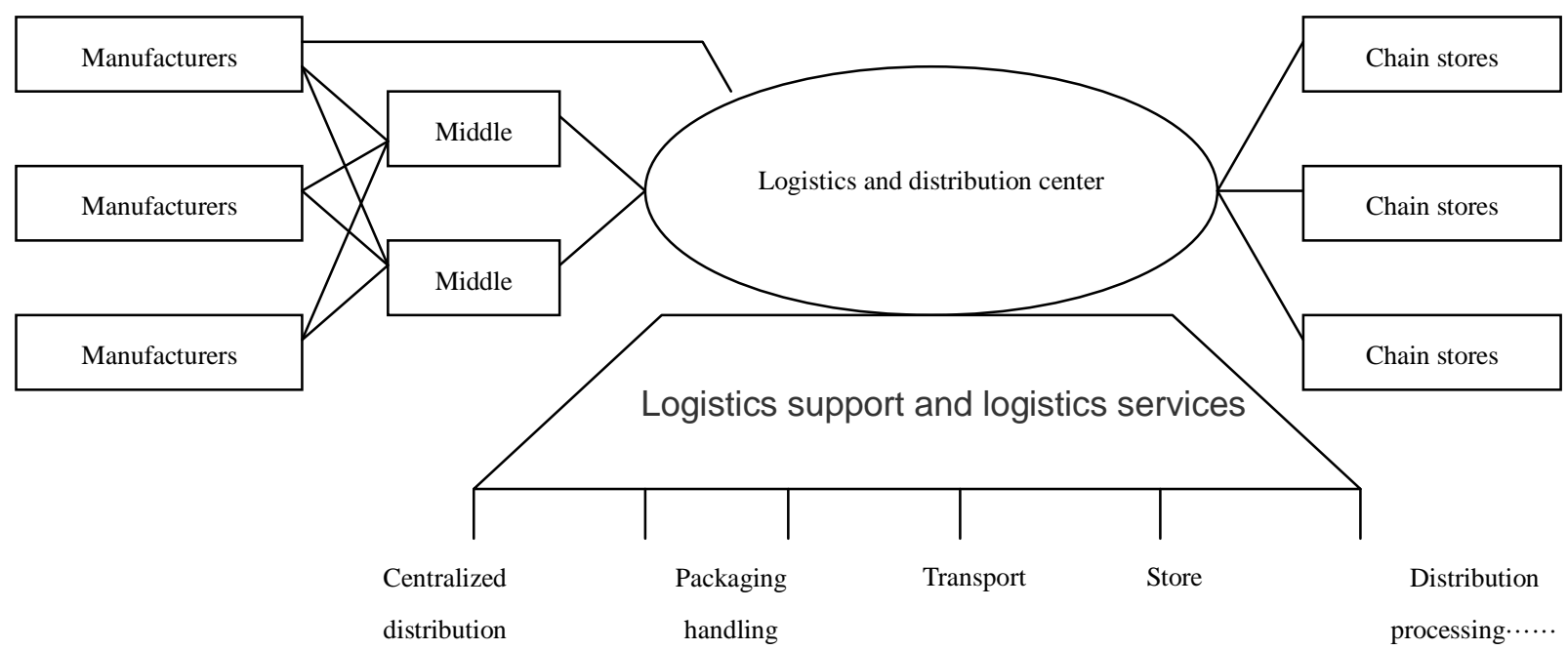

Figure 2. Ideal supply chain structures.

5) Implementation of the efficient category distribution strategy. The category distribution strategy is the configuration of goods retailer in the assistance of the manufacturer, customer preferences and brand performance, it not only can improve the distribution of goods structure, also can increase the sales of goods and customer satisfaction.

6) Train delivery personnel very well. Maqun logistics distribution center consisted of the strategic level, the management and operation of layer three-level employees. Different types of training for different levels of staff should be reasonable arranged, to mobilize the enthusiasm of the staff, the staff carry out their duties, whatever.

\section{Summary}

For enterprises with small number of chain stores, to build their own distribution centers, the cost of the investment is very large, the flow of funds will be problems; if use the third-party logistics, it is not an effective strategy for long-term development of the enterprise, the profits divert. Joint distribution can be used in this case, can not only solve the problem of insufficient funds, through the joint between the retail enterprise to strengthen the competitiveness of the group of business alliances, it is very beneficial for small and medium-sized investment entities. In short, the supermarket chains should choose the delivery mode for their own development according to their own situation.

\section{REFERENCES}

[1] S. Q. Li, “Chain Operations Management Practices,” Economic Management Press, Beijing.

[2] Y. Li, "Transportation and Distribution Management," Science Press, Beijing, 2010

[3] K. Yao, "Heritage, Zou Wei Supermarket Business Management Practices,” Science and Technology Press, Liaoning, 2004.

[4] F. C. Cao, "Supermarket Chain Logistics and Distribution Model to Explore,” Economic Market, Vol. 1, 2007.

[5] N. Wang, "Chain Logistics Problems and Countermeasures,” Management World, Vol. 11, 2008. 